\title{
Business Informatics Principles
}

\author{
Simona Sternad Zabukovšek, Polona Tominc, \\ and Samo Bobek
}

\begin{abstract}
Business informatics consists of two major areas which are developing separately but are closely related and also to some extent integrated within information systems architecture in organisations. The first area is business solutions as core information systems for support of business operations - they consist of Enterprise resources planning solutions (ERP), Customer relationship management solutions (CRM) and other specialised solutions. The second area is Business Intelligence (BI). After describing the basic concepts of these information solutions/business information systems and their functionality, the chapter explains the emerging integration of business informatics and geo-informatics. Developments provided by solution providers are analysed and discussed. The chapter concludes with a bibliometric analysis of research which shows areas and dynamics of business informatics and GIS integration.
\end{abstract}

\section{Keywords}

Enterprise resource planning - ERP - Business intelligence - BI - Geographical information systems - GIS

\section{S. S. Zabukovšek $(\bowtie) \cdot$ P. Tominc $\cdot$ S. Bobek} Faculty of Economics and Business, University of Maribor, Maribor, Slovenia

e-mail: simona.sternad@um.si; polona.tominc@um.si; samo.bobek@um.si

\subsection{Introduction}

Modern organisation is viewed as a group of people with a common goal, which has certain resources at its disposal to achieve goals. In the traditional approach, the organisation is divided into different units based on the business functions, such as manufacturing or production department, production planning department, purchasing department, sales and distribution department, finance department, research and development (R\&D) department etc. (Anderegg 2000; Sneller 2014). These departments have not been integrated through business processes, and each department has been a »silos « and has its own goal and objectives (Magal and Word 2011). They had their departmental information systems with their own databases where they collected data and performed the analysis. Because of that the information was created or generated by the various departments, in most cases is available only to the top management and not to other departments (Anderegg 2000). Departments didn't know what others do, and sometimes the departments' objectives could be conflicting. When all departments don't know what other departments are doing and for what purpose, different kinds of conflicts often arise.

Global competition requires companies to behave as an integrated organisation - the entire organisation is considered an integrated enterprise system and is supported by enterprise information systems. Information about all business 


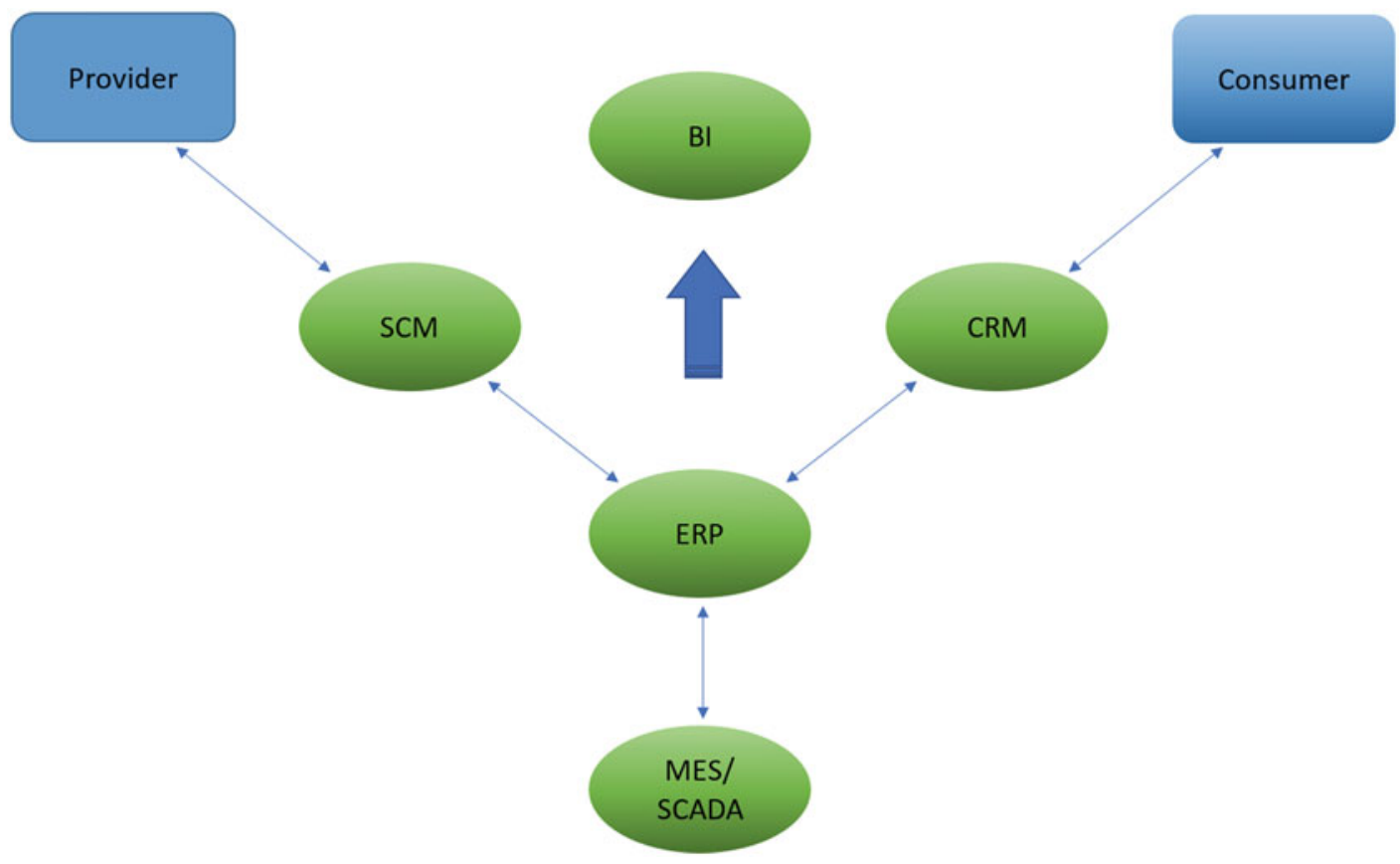

Fig. 4.1 Business information systems

functions is stored centrally and is available to all departments (Bradford 2016). This transparency and information access ensure that the departments are no longer working in isolation pursuing their own departmental goals. Each part of the enterprise knows what others are doing, why they are doing it and what should be done to move the company towards the common goal (Magal and Word 2011). Therefore, the prerequisite for successful modern organisations is enterprise information systems.

Enterprise information systems can be divided into two categories: enterprise information systems for operational support which are focused in business transactions (online transaction processing - OLTP) and enterprise information systems for management support (online analytical processing - OLAP) (Fig. 4.1). The first category - enterprise information systems for operational support - consists of the following types: manufacturing resource planning (MRP); enterprise resources planning (ERP) - systems used to register most of the events in the enterprise concerning economics and finance issues as well as business processes (supply, production and sale); customer relationship management (CRM) and some other specialised enterprise information systems needed in certain industries. The second category - enterprise information systems for management support - is also referred as business intelligence (BI) - systems for the analysis of the company's condition, they support higher information functions; there are also other specialised information systems which provide specialised functionality. In this category one of the most important is Geographic(al) information systems (GIS) which enable spatial location of existing infrastructure etc. (Stepniak and Turek 2014). Companies can use various combinations of these systems, where the mixture depends on the industry. This usually leads to the integration of information systems in the enterprise.

In the next section, the major categories of enterprise information systems, namely Enterprise resource planning systems (ERP) and Customer relationship management systems (CRM) will be explained, and concepts of their integration with GIS announced and implemented by vendors will be discussed. In the section that follows the Business intelligence systems will be 
explained and their integration with Spatial analytics, sometimes also referred to as Geospatial Business Intelligence foreseen and implemented by vendors will be summarised and discussed. In the last section, the findings of a bibliometric analysis of scientific publishing in these areas will be presented what will show the state of the art of research.

\subsection{Enterprise Information Systems for Operational Support}

\subsubsection{Enterprise Resource Planning (ERP) Information Systems and Customer Relationship Management (CRM) Information Systems}

Enterprise resource planning (ERP) solutions usually refer to the business-management support software. Typically, this is an integrated application which an organisation can use to collect, store, manage and interpret data from their daily business activities (Bradford 2016). ERP solutions provide an integrated and continuously updated view of core business processes using a common database. ERP solutions track business resources-cash, raw materials, production capacity-and the status of business commitments: orders, purchase orders, and payroll. The applications that form the system share data across various departments (manufacturing, purchasing, sales, accounting, etc.) that provide the data (Almajali et al. 2016). ERP facilitates information flow between all business functions and manages connections to outside stakeholders (Bidgoli 2004). ERP predicts and balances demand and supply. It is an enterprise-wide set of forecasting, planning and scheduling tools, which links customers and suppliers into the supply chain, employs proven processes for decisionmaking and coordinates business areas such as sales, marketing, operations, logistics, purchasing, finance etc. Most ERP systems incorporate best practices which means the software reflects the vendor's interpretation of the most effective way to perform each business process (Monk and Wagner 2009; Sneller 2014). The most widely used integrated solutions for business in companies from almost all industries worldwide are Enterprise Resource Planning (ERP) solutions. About $90 \%$ of the Fortune 500 companies use ERP solutions (HubPages 2018). A number of ERP implementations and because of that also a number of ERP users within organisations is growing very fast as well; employees are using ERP solutions daily at their work.

The organisation Gartner Group first defined ERP as a concept more than 25 years ago (Montgomery et al. 2018). ERP systems initially focused on automating back-office functions (functions which did not directly affect customers), while front office functions (functions which directly dealt with customers), e-business or supplier relationship management (SRM) became integrated later when the Internet enabled the simplified communication with external parties.

An ERP system covers the following common functional areas. In many ERP systems these are called and grouped as ERP modules (Anderegg 2000; Bradford 2016; see Fig. 4.2):

- Finance \& Accounting: general ledger, fixed assets, payables including vouchering, matching and payment, receivables, cash management and collections, cash management, and financial consolidation.

- Management Accounting: budgeting, costing, cost management, and activity-based costing.

- Human resources: recruiting, training, rostering, payroll, benefits, retirement and pension plans, diversity management, retirement, and separation.

- Manufacturing: engineering, bill of materials, work orders, scheduling, capacity, workflow management, quality control, manufacturing process, manufacturing projects, manufacturing flow, and product life cycle management.

- Order Processing: order to cash, order entry, credit checking, pricing, available to promise, 


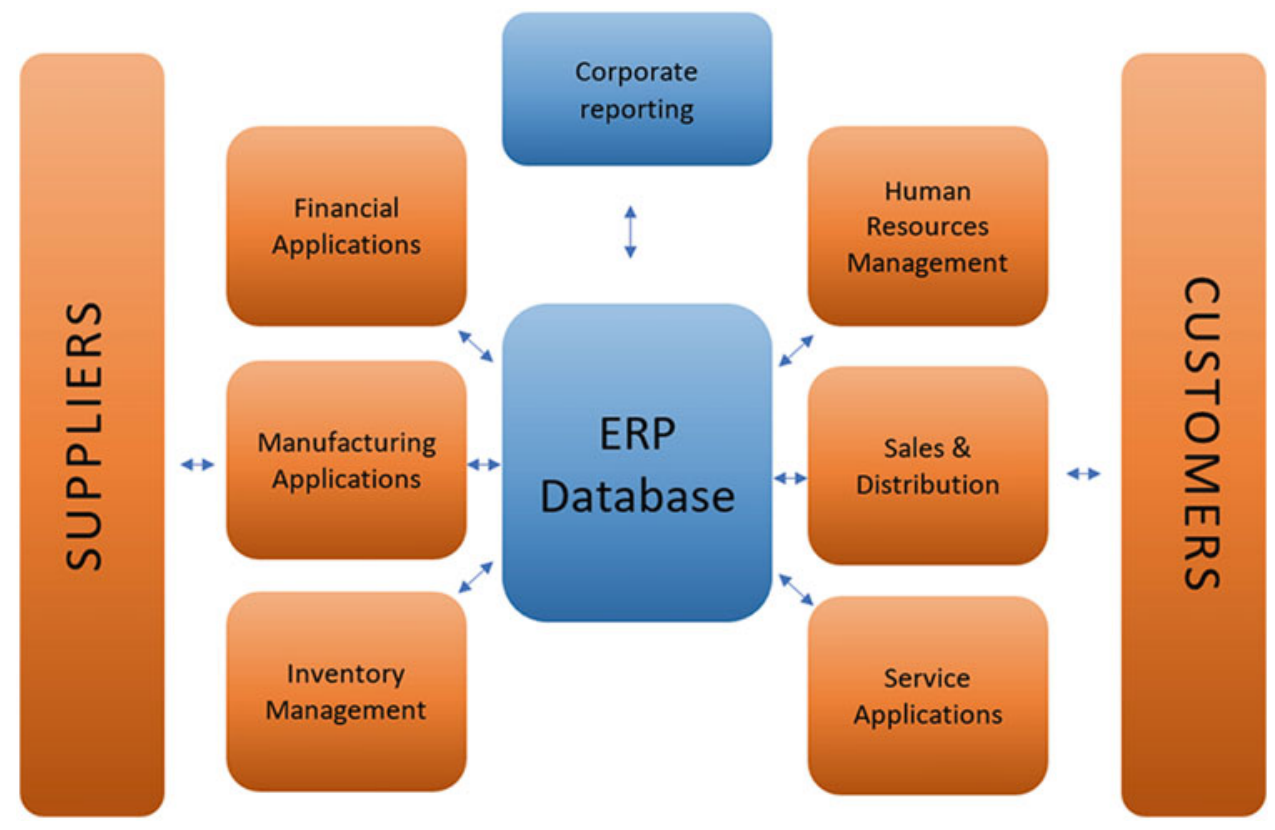

Fig. 4.2 Modules of enterprise resource planning (ERP) information systems

inventory, shipping, sales analysis and reporting, and sales commissioning.

- Supply chain management: supply chain planning, supplier scheduling, product configurator, order to cash, purchasing, inventory, claim processing, and warehousing (receiving, put away, picking and packing).

- Project management: project planning, resource planning, project costing, work breakdown structure, billing, time and expense, performance units and activity management.

- Customer Relationship Management (CRM): sales and marketing, commissions, service and customer contact.

- Data services: various "self-service" interfaces for customers, suppliers and/or employees.

In 2013 the organisation Gartner Group (Ganly et al. 2013) introduced the term "postmodern ERP" (also called as the eXtended ERP xERP). According to Gartner's definition of the postmodern ERP strategy, legacy systems of monolithic and highly customised ERP suites, in which all parts are heavily inter-dependent, should be replaced by a mixture of both cloudbased and on-premises applications, which are more loosely coupled and can be easily exchanged if needed. The organisation Gartner Group has evolved its definition over time and now defines ERP as an application strategy focused on several distinct enterprise applications suites. They segment ERP into four major business process support areas: financial management systems, human capital management (HCM), enterprise assets management (EAM), and manufacturing and operations (Montgomery et al. 2018). Key characteristics of postmodern ERP are (ACC Software Solutions 2018):

- it delivers business agility and flexibility;

- flexibly coupled applications;

- not a single product suite;

- plays well with others through APIs and pre-built integrations;

- modern, web and mobile-friendly user interface (UI);

- flexible, deployment options (on-premises, private/public cloud, or hybrid); 
- business-specific integrations;

- reduced complexity of the core ERP;

- SaaS deployment means near "painless" upgrades; improved business outcomes;

- and flexible licensing options.

Early ERP providers focused on large enterprises, but smaller enterprises are increasingly using ERP systems as well (Phillips and Ryan 2013). Main reasons for the growth of the ERP market are (Bradford 2016): it enables improved business performance (i.e. cycle time reduction, increased business agility, inventory reduction), supports business growth requirements (i.e. new product or product lines, new customers, global requirements including multiple language and currencies), provides flexible, integrated, real-time decision support (i.e. improve responsiveness across the organization), eliminates limitation in legacy systems (i.e. century dating issues, fragmentation of data and processing, inflexibility to change, insupportable technologies), takes advantage of small and medium-size organizations (i.e. increased functionality at a reasonable cost, cloud computing compatibilities, vertical solutions). These are just some of the reasons for the growth rate of the ERP market. Company SAP is a market leader, followed by Oracle, Sage, Infor and Microsoft (SMRC 2017). It is expected that ERP will remain the important basic software in the organisations (Pelphrey 2015).
Some big organisations require more advanced support for customer relationship management which is beyond basic functionalities of ERP. Such organisations are using customer relationship management (CRM) solutions to obtain advanced functionality (Fig. 4.3). CRM solutions compile data from a range of different communication channels, including a company's website, telephone, email, live chat, marketing materials, and more recently, social media (Starzyczna et al. 2017; Yerpude and Kumar Singhal 2018). Through the CRM approach and the systems used to facilitate it, businesses learn more about their target audiences and how to best cater to their needs.

The primary goal of CRM systems is to integrate and automate sales, marketing, and customer support (Lizzote 2017). Therefore, these systems typically have a dashboard that gives an overall view of the three functions on a single customer view, a single page for each customer that a company may have. The dashboard may provide client information, past sales, previous marketing efforts, and more, summarising all the relationships between the customer and the firm. Operational CRM is made up of 3 main components: sales force automation, marketing automation, and service automation (Buttle and Maklan 2015).

- Salesforce automation works with all stages in the sales cycle, from initially entering contact information to converting a prospective client

Fig. 4.3 Features of ERP and CRM systems

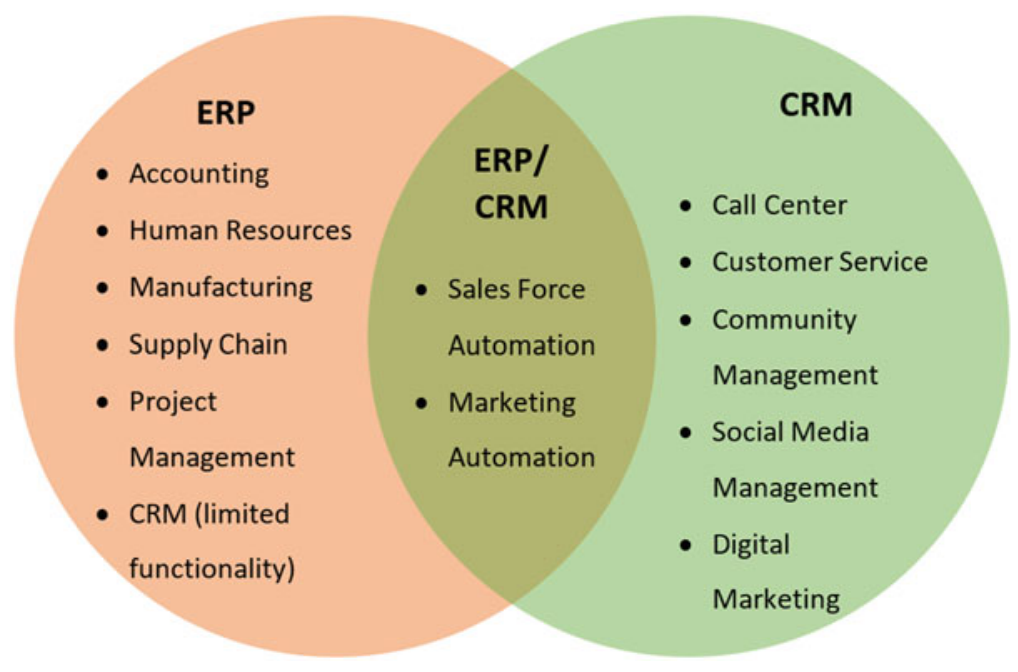


into an actual client (Yerpude and Kumar Singhal 2018). It implements sales promotion analysis, automates the tracking of a client's account history for repeated sales or future sales and coordinates sales, marketing, call centres, and retail outlets. It prevents duplication of efforts between a salesperson and a customer and automatically tracks all contacts and follow-ups between both parties.

- Marketing automation focuses on easing the overall marketing process to make it more effective and efficient. CRM tools with marketing automation capabilities can automate repeated tasks, for example, sending out automated marketing emails at certain times to customers, or posting marketing information on social media. The goal of marketing automation is to turn marketing leads to a full customer. CRM systems today also work on customer engagement through social media.

- Service automation is part of the CRM system that focuses on direct customer service technology. Through service automation, customers are supported through multiple channels such as phone, email, knowledge bases, ticketing portals, FAQs, and more.

The role of analytical CRM systems is to analyse customer data collected through multiple sources and present it so that business managers can make more informed decisions (Wan and Xie 2018). Analytical CRM systems use techniques such as data mining, correlation, and pattern recognition to analyse customer data (Chorianopoulus 2016). These analytics help improve customer service by finding small problems which can be solved, perhaps, by marketing to different parts of a consumer audience differently (Nussbauman 2015).

\subsubsection{Enterprise Information Systems and GIS Integration}

Existing software architectures often separate enterprise information systems and GIS. As a result, spatial processes and business processes are also perceived as distinct processes (Treiblmayer et al. 2011). As explained previously, ERP solutions usually refer to the business-management support software. Typically, this is an integrated application which an organisation can use to collect, store, manage and interpret data from their daily business activities. On the other hand, GIS are information systems for capturing, storing, checking, and displaying data related to positions. GIS is often isolated in information system landscapes. But decision support requires integrated workflows that cover business processes and spatial processes. Since most business data has a geographic or spatial component that can be geo-referenced on a GIS map to visualise, understanding and interpretation of data through a spreadsheet or table is not possible (Abou-Ghanem and Arfaj 2008). Although the GIS can include data about daily business activities, for example, actual and potential customers on the map for market analysis etc., they usually are not part of ERP, because of the complexity involved in handling each system. By integrating ERP systems for workflow management and GIS for location-based information management, this integration can bring many advantages in both fields. Abou-Ghanem and Arfaj (2008) pointed out that this could result in a loss of opportunities to leverage spatial analysis capabilities of GIS and business transaction management tools of ERP systems. Therefore, in recent years the level of interest in integrating GIS with ERP and legacy systems has been growing significantly. By visualising relationships, connections and patterns in business data, GIS can help to make informed decisions and increase efficacy. This makes ERP and GIS systems an integral part of a powerful IT strategy.

Abou-Ghanem and Arfaj (2008) pointed out that including GIS into business process offers features that fall into the following categories:

- Provision of geographic context to business decisions by integrating business data with geodatabases and feature tables.

- Linking business functions in an ERP system with geo-processes combined functionality that is distributable across the software architecture. 
- Fusion of business and geographic information and functionality in the common operational picture on both high and low levels.

With integration, a user can visualise ERP system data within the GIS and can get direct access to the GIS within the ERP system. A user can accomplish more since he/she has the ability to make decisions by visualising the output of both systems on a screen in a simple visible manner, without the need to switch between systems and correlate the data between several systems. Specific ERP and GIS capabilities include functions such as (Horwitt 2009):

- Map relationships between customers and markets, and plant and warehouse locations. This enables companies to manage transport costs and product distribution better, as well as to optimise the location of new manufacturing facilities (for example, putting a site in a low-rent district near a highly populated area).

- Analyse supply chain, distribution and service vulnerabilities from a geographic perspective. Some automakers have been using GIS demographic data to help figure out which dealerships to close. Companies can also analyse service response time by region, identifying areas where it tends to be slow. They can then institute training programs or hire more people in those regions.

- Sort customers by attributes such as a preference for a product or attribute (low cost, low calorie, luxury), then map those preferences by region, state or neighbourhood and use the data, in combination with demographic data, to focus marketing, sales or distribution. Example of sales by customer visualised on the map is shown in Fig. 4.4.

Organizations that integrate GIS with ERP systems include (ESRI 2007): utilities (water, electric, gas, waste, recycling), local government, oil and gas production, defence and public security, service providers (routing and logistics), real estate, forestry and forest products, waterways, airports, ports etc. With systems linked, the user can do an array of functions that could impact corporate running cost by accomplishing the following (Patel and Doctor 2013):

- Improve resource utilisation, analysis, safety and asset integrity through an ability to represent work orders and notifications at their exact location on a GIS map.

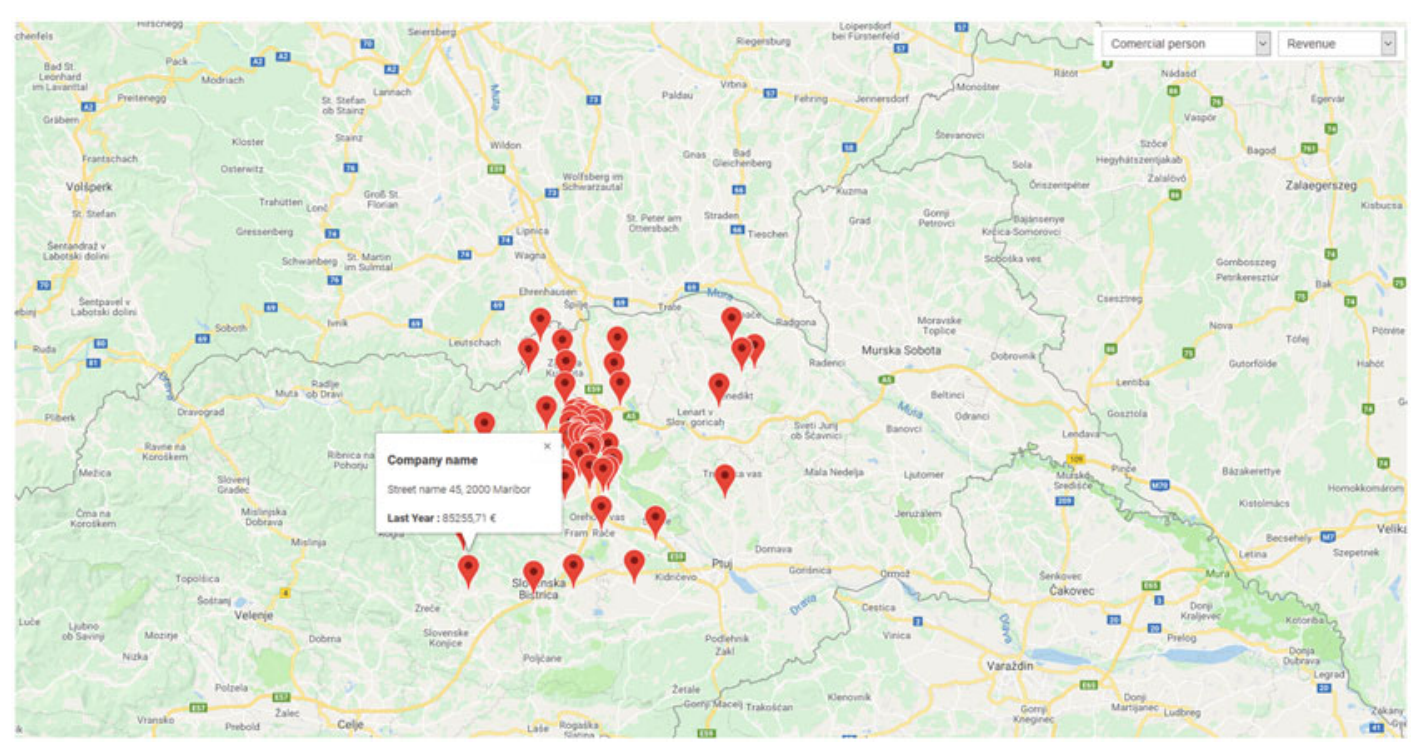

Fig. 4.4 Sales by customers visualised on a map 


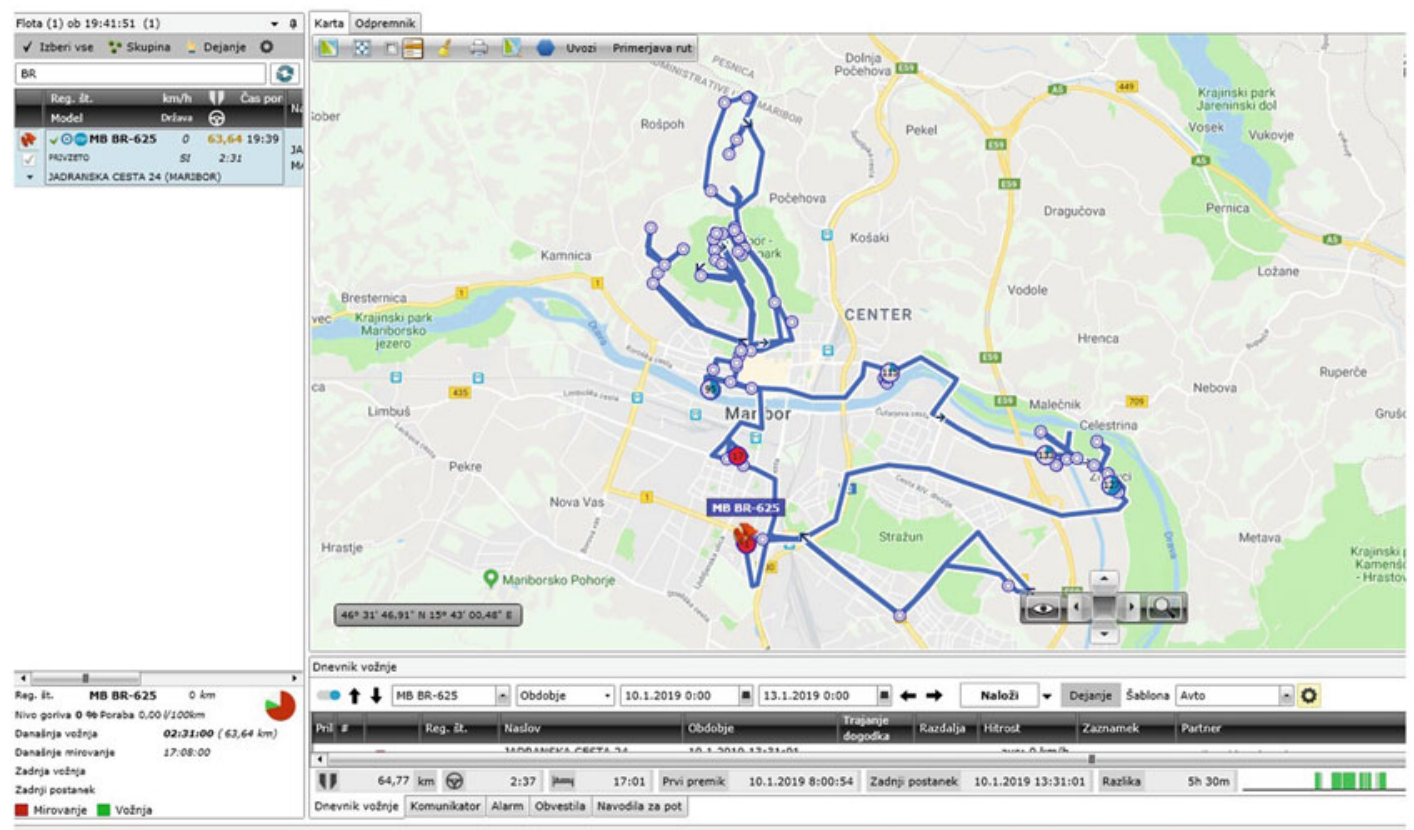

Fig. 4.5 Visualisation of the daily route of the employee

- Improve operational efficiency (e.g. safety, dispatching) by representing work activities that impact an area as polygons on the map and identification of shortest routes.

- Improve workforce productivity by providing broader browser-based access to ERP and GIS-based assets, maintenance, and customer information.

- Reduce service costs by expanding a no-line self-service portal with essential business processes (e.g. report fault equipment)

- Elevate customer service and decision-making with expanded access to ERP data from the GIS maps.

Another example is the interaction between CRM and GIS. GIS system Esri Maps for Dynamics CRM provides fast and easy integration of Esri maps and the Esri platform into Microsoft's Dynamics CRM product. With Esri Maps we can see our CRM data on a map and visualise it in more meaningful way (Fig. 4.5), learn more about the areas and markets in which our CRM data reside, use the map to enhance analysis, and share all of this with others in our organisation. It includes the following features (ESRI 2018) - the user can:

- map CRM data to see easily where concentrations of customers or constituents exist;

- customise maps and add them to Dynamics CRM dashboards, access rich collection of base maps, demographic maps, image services, and data;

- visualise neighbourhood demographics using pop-ups;

- calculate routes and build travel activity based on customer/prospect location;

- geocode, geo-enabled, and geo-enrich CRM data using a Locate workflow;

- visualise CRM data by grouping according to attribute;

- save CRM data into views based on geographic selection and then use those views for other CRM activities like adding to marketing lists and sending emails;

- share maps with the rest of the organisation using ArcGIS Online; 
Fig. 4.6 ERP/CRM and GIS-based asset/resources management

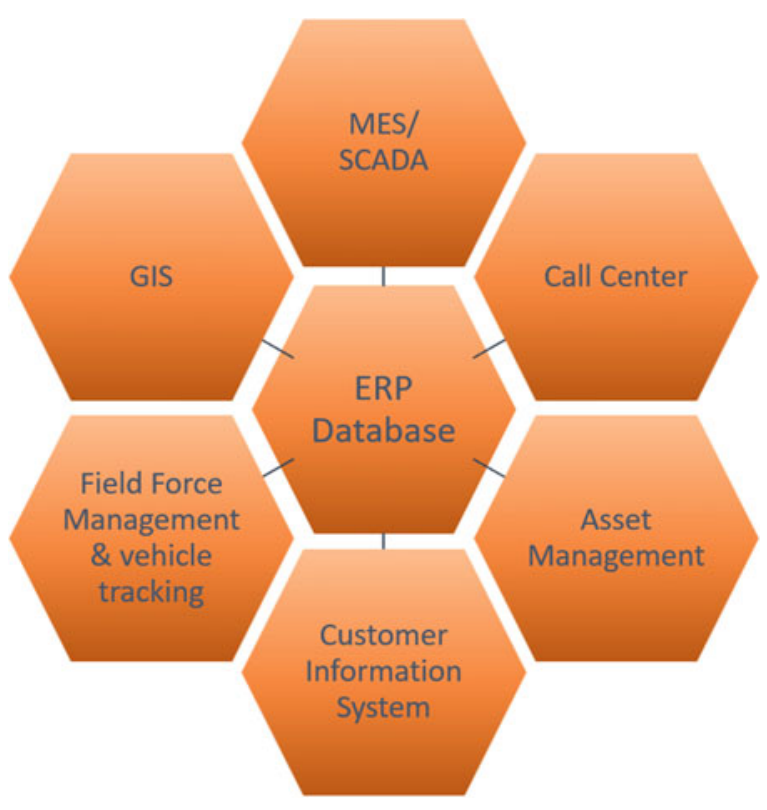

- single sign-on capability (with CRM on-premises, organisations can use the same login for their organisation, for CRM, and for ArcGIS Online or with CRM Online, organisations can use the same login for their organisation and ArcGIS Online).

Both ERP/CRM and GIS industry leaders have identified several options and methods for integration of GIS and ERP systems (Fig. 4.6). The options and methods are derived based on the system functions and ERP objects. They can build or purchase software connectors that directly connect a given ERP and GIS package. They can use passive middleware, which is fine if they can stick with generic ERP and GIS and don't need to customise their processes. Or they can deploy frameworks for comprehensive integration with a given GIS package from an ERP vendor (Horwitt 2009).

For example, the most successful integration GIS - ERP was done by Esri and SAP, the industry leaders of GIS and ERP systems respectively, has resulted in the identification of five main technical interfaces available for integration (Abou-Ghanem and Arfaj 2008; Patel and Doctor 2013):
- SAP RFC (Remote Function Calls) connectors, which allow for remote calls between SAP ERP and ESRI GIS software.

- Third-party connectors include the Way Control Broker (CB) from Information Builders which is component-based and allows director connection to packages and legacy back-end systems. They provide an application level approach for greater control, performance and scalability.

- SAP generic GBC (GIS Business Connector) is a passive middleware that mediates between SAP solution and ESRI GIS. The method is best used when there is flexible processing modelling with existing methods in both software.

- Third-party Enterprise Application Integrators (EAI) is generally defined as the combination of platforms, business processes, standards and applications that results in the seamless integration of two or more enterprise systems. It can be used when there are non-standard processes that require custom development.

- SAP EAI called SAP Exchange Infrastructure is used to facilitate the exchange of information between both and can be used to mediate 
between entities with varying requirements in terms of protocols, connectivity and format.

- Vendors partner solutions, such as SICADAPX (ESRI's partner solution), which is an EAI that integrates ESRI's GIS with SAP's ERP modules.

Another point of integration is layers of integrations which could be (Yaptenco et al. 2005): master data synchronisation, process integration, desktop integration, integrated web applications (portals) and/or integrated mobile applications. The process of selecting an integration method and options depends on several considerations such as development cost and corporate directions for integration. Industry leaders have recommended the following selection criteria:

- Corporate standards in exposing business data either on real-time bases or using previously prepared reports from a business warehouse.

- Data exchange technology adopted on the corporate level such as using Service Oriented Architecture (SOA) and web services, application integrators or third-party solutions.

- Business process requirements such as data visualization or data editing and updating.

- Technology availability based on ERP objects to be integrated.

- Vendors recommendation methods.

In addition to these criteria, also development cost plays an important role in the selection process. Some solutions could provide rapid deployment, but the cost of development, consulting and maintenance could be high, and this could have a stronger impact on the technology and methods of integration.

But the most important part of ERP integration is to define the business processes and the corresponding business requirements. Yaptenco et al. (2005) define the user cases and business processes, the user interface requirements, the data model requirements, select technical connector approach based on business processes and requirements and design business logic in conjunction with the requirements and technical connector approach.

Starting from software development patterns and three-tier applications development, there are three layers of software integration: data integration, service integration and process integration (Litan et al. 2011). They also added that the level of complexity rises from data to process integration, and the level of abstraction as well. Service and process integration lead to the completeness and coherence of integrated systems. The most commonly used approaches in service integration are SOA (Service Oriented Architecture) and ESB (Enterprise Service Bus). The concept of SOA provides an approach to integrate heterogeneous software applications (Treiblmayer et al. 2011). SOA allows interacting software components to be loosely-coupled. Web service interfaces can facilitate the exchange of data and services between GIS and enterprise information systems. Thus, a workflow can be established that integrates the business process as it is covered by the enterprise information system and the spatial process as the GIS covers it. ESB generally provides an abstraction layer on top of an implementation of an enterprise messaging system, which allows developers to exploit the value of messaging without allowing writing code (Litan et al. 2011). Unlike the classical EAI approaches, ESB cuts the number of interfaces for interconnection between different systems, being capable of translating interfaces. Therefore, technological progress in Internet technology and the development of the SOA concept made it possible to embed GIS applications into common activities as well as integrating them with different systems such as ERP and CRM. Benefits of integration are efficient to use of resources, reduced costs, enhancement of customer satisfaction, increased interoperability of different departments, quick and accurate analysis and better business process management.

As we mentioned before the synergy between GIS and ERP/CRM systems offers competitive advantages to any enterprise (Fig. 4.7) in supply chain management and marketing areas. In supply chain management offer shorter order cycle, more reliable deliveries, better warehouse 


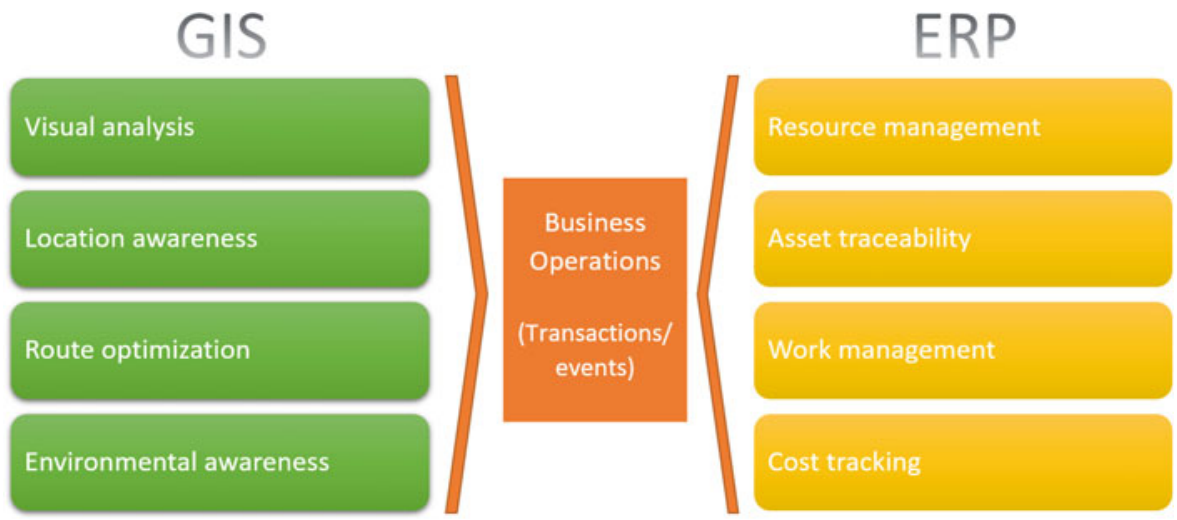

Fig. 4.7 ERP systems and GIS integration

management and lower transportation costs (Aydin and Sarman 2006). In marketing, offer segmentation of customer by lifestyle and product category, implementation of pricing policy depending on location, site selection and delivery routing, development of target promotions and campaigns, geocoding of customers, understanding of customer spending (Hessa et al. 2004).

\subsection{Information Systems for Management Support}

\subsubsection{Business Intelligence Systems}

The term business intelligence (BI) emerged in the mid-1990s to describe the concepts of transforming business data from an information system in which operational data of business transactions are captured and stored into a database which is being used for management support (Sherman 2015). BI comprises the solutions and technologies used by organisations for the business data analysis used in management reporting. Business intelligence can be used by organisations to support a wide range of business decisions - ranging from operational to strategic. $\mathrm{BI}$ is a priority for organisations interested in gaining a competitive advantage. BI leverages corporate data and empowers managers with insights needed for sound business decisions. BI technologies provide historical, current and predictive views of business. BI technologies can handle large amounts of structured and sometimes unstructured data to prepare business reports for managers (Howson 2014). BI is most effective when it combines data derived from external data sources (external data) with data from company internal data sources such as financial and operations data (internal data). When combined, external and internal data can provide a holistic picture which, in effect, creates an "intelligence" that cannot be derived from any partial set of data. BI tools empower the organisation to gain insight into new markets, to assess demand and suitability of products and services.

Business intelligence (BI) and business analytics (BA) are sometimes used interchangeably, but there are distinctions between them. The term business intelligence usually refers to collecting business data for business reporting, and online analytical processing (Trieu 2017). Business analytics, on the other hand, refers to statistical and quantitative tools for explanatory and predictive modelling.

BI/BA systems use the extraction, transformation, and loading (ETL) processes which are used to retrieve data from information systems on an operational level. The BI processes collect data directly from the point where it's generated. Data can be originated from many types of systems and applications, including business software such as enterprise resource management (ERP) or customer relationship management (CRM) applications, plain text files, or office application 
files such as spreadsheets. The data is moved or forwarded from its source location to a data warehouse or data mart. During this process, which is called data integration, following subtasks take place. A data quality process ensures that the information remains consistent, accurate, and "clean"- i.e., there is a process to avoid/correct/detect problems within the data that is being moved to the data warehouse. A data transformation modifies the structure of the data to satisfy the conditions imposed by the design of the data warehouse and to ensure the consistency of all information. The load process allocates the information into an information repository (such as a data warehouse or data mart) (Trieu 2017).

Users interact with an easy-to-use interface to use of tools for querying, reporting, online analytical processing tool (OLAP) etc. The same interface is also the gateway into a structured reporting environment that distributes operational reports and business decision results throughout the organisation (Fig. 4.8).

Reporting, a main task of BI, has become more graphics intensive. Business graphics, typically charts, are now a common component of reports. Access to BI data became more timely, because of that graphic dashboards were developed to monitor key business processes. Dashboards, named for their similarity to automobile dashboards, convey operational information at a glance. Dashboards and scorecards nowadays comprise only part of the available tools. Interactivity between BI tools and office applications is increasing and extending BI functionality, and mobile technologies are taking their own place in the equation, with BI providers now capable of distributing BI information to mobile devices. All these trends in the data visualisation phase are enabling more people within the organisation to become BI software consumers or users (Chung et al. 2002).

A primary goal of data visualisation used in $\mathrm{BI}$ systems is to communicate information clearly and efficiently via statistical graphics, plots and information graphics. Numerical data may be presented using dots, lines, or bars, to communicate a quantitative message visually. Effective visualisation helps users analyse and reason about data and evidence. It makes complex data more accessible, understandable and usable. Users may perform analytical tasks, such as comparisons or understanding causality, and the design principle of the graphic (i.e., showing comparisons or showing causality) follows the task. Tables are generally used where users will look up for a specific measurement, while charts of various types are used to show patterns or relationships in the data for one or more variables.

Dashboards are using principles described above, and they often provide at-a-glance views of Key Performance Indicators (KPIs) relevant to an objective or business process also referred to

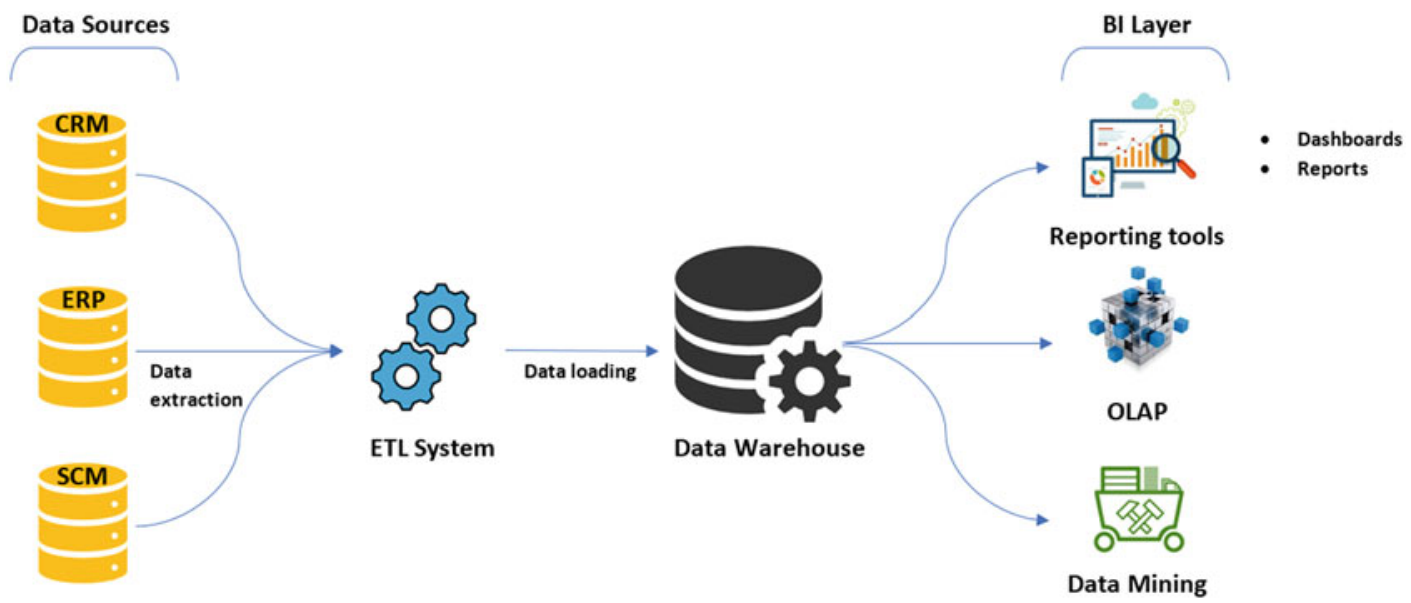

Fig. 4.8 Business intelligence system 
as Critical Success Factors (CSFs). The "dashboard" is often displayed on a web page which is linked to a database that allows the report to be constantly updated. For example, a manufacturing dashboard may show numbers related to productivity such as the number of parts manufactured, or a number of failed quality inspections per hour. Similarly, a human resources dashboard may show numbers related to staff recruitment, retention and composition, for example, number of open positions, or average days or cost per recruitment. The term dashboard originates from the car dashboard where drivers monitor the major functions at a glance via the instrument cluster. Digital dashboards allow managers to monitor the contribution of the various departments in their organisation. To gauge exactly how well an organization is performing overall, digital dashboards allow to capture and report specific data points from each department within the organisation, thus providing a "snapshot" of performance.

Dashboards can be divided according to the role and are either strategic, analytical, operational, or informational (Few 2006). Strategic dashboards support managers at any level in an organisation and provide a quick overview that decision makers need to monitor the "health" and opportunities of the business. Dashboards of this type focus on high-level measures of performance, and forecasts. Strategic dashboards benefit from static snapshots of data (daily, weekly, monthly, and quarterly) that are not constantly changing from one moment to the next. Dashboards for analytical purposes often include more context, comparisons, and history, along with subtler performance evaluators. Analytical dashboards typically support interactions with the data, such as drilling down into the underlying details. Dashboards for monitoring operations are often designed differently from those that support strategic decision making or data analysis and often require monitoring of activities and events that are constantly changing and might require attention and response at a moment's notice.

Digital dashboards may be laid out to track the flow inherent in the business processes that they monitor. Graphically, users may see the high-level processes and then drill down into low-level data. This level of detail is often buried deep within the corporate enterprise and otherwise unavailable to the senior executives (Chen et al. 2012).

Balanced Scoreboards and Dashboards have been linked together as if they were interchangeable. However, although both visually display critical information, the difference is in the format: Scoreboards can open the quality of operation while dashboards provide calculated direction. A balanced scoreboard has what they called a "prescriptive" format. It should always contain these components:

- Perspectives - groupings of high-level strategic areas

- Objectives - verb-noun phrases pulled from a strategy plan

- Measures - also called Metric or Key Performance Indicators (KPIs)

- Spotlight Indicators - red, yellow, or green symbols that provide an at-a-glance view of a measure's performance.

Each of these sections ensures that a Balanced Scorecard is essentially connected to the business's critical strategic needs.

With the dynamic economic landscape, businesses are increasingly looking for ways to do more with less and maximise their existing assets to extract the most value. To achieve this, BI has been a significant component in many organisations' technology portfolios. Business intelligence can provide a pro-active approach, such as alert functionality that immediately notifies the end-user if certain conditions are met. For example, if some business metric exceeds a pre-defined threshold, the metric will be highlighted in standard reports, and the business analyst may be alerted via e-mail or another monitoring service. This end-to-end process requires data governance, which should be handled by the expert. Well-implemented BI allows organisations to focus on what's important and make business decisions to drive performance. 


\subsubsection{Business Intelligence and Spatial Analytics}

Historically, business intelligence (BI) and geographic information system (GIS) technology have followed separate development and implementation paths. Customer requests for a complete operational picture and the ability to be more proactive have led to the combination of these two technologies. Regulatory requirements have also raised the visibility of both technologies within many organisations. In response to BI and GIS users, leading BI providers have been integrating the two technologies and providing innovative solutions to a growing number of end users. The users are responding with new applications that leverage the synergy of the combined technologies (Bimonte et al. 2010).

Organisations today are collecting data at every level of their business and in volumes that in the past were unimaginable. On the other hand, it is predicted that nearly $80 \%$ of all data has a kind of spatial component. Traditionally such data would be presented to users in long reports, either with graphs and pie charts or in spreadsheet format. Today the complex interrelationships of multidimensional data, integrating spatial data and visualisation are offering high impact insight to business intelligence users.

As BI has matured, the reach of GIS has expanded significantly as well (Posthumus 2008). In addition to speciality IT groups, GIS provides agility to a multitude of departments in many industries. It allows users to visualise and intelligently analyse historically underutilised data in ways not typically seen in traditional BI implementations (Gideon Adewale et al. 2016). Given the complementary natures of BI and GIS, the adoption of geographic analysis to enhance business intelligence is growing rapidly. Through the fusion of these two enterprise technologies, organisations can visualise and analyse key business data through "smart" maps to discover patterns and trends that would have been easily overlooked with traditional BI tables and charts (Fig. 4.9).

Humans think visually, therefore spatially. While traditional methods used to represent information and gain insight have been helpful, they have been limited in capabilities when it comes to

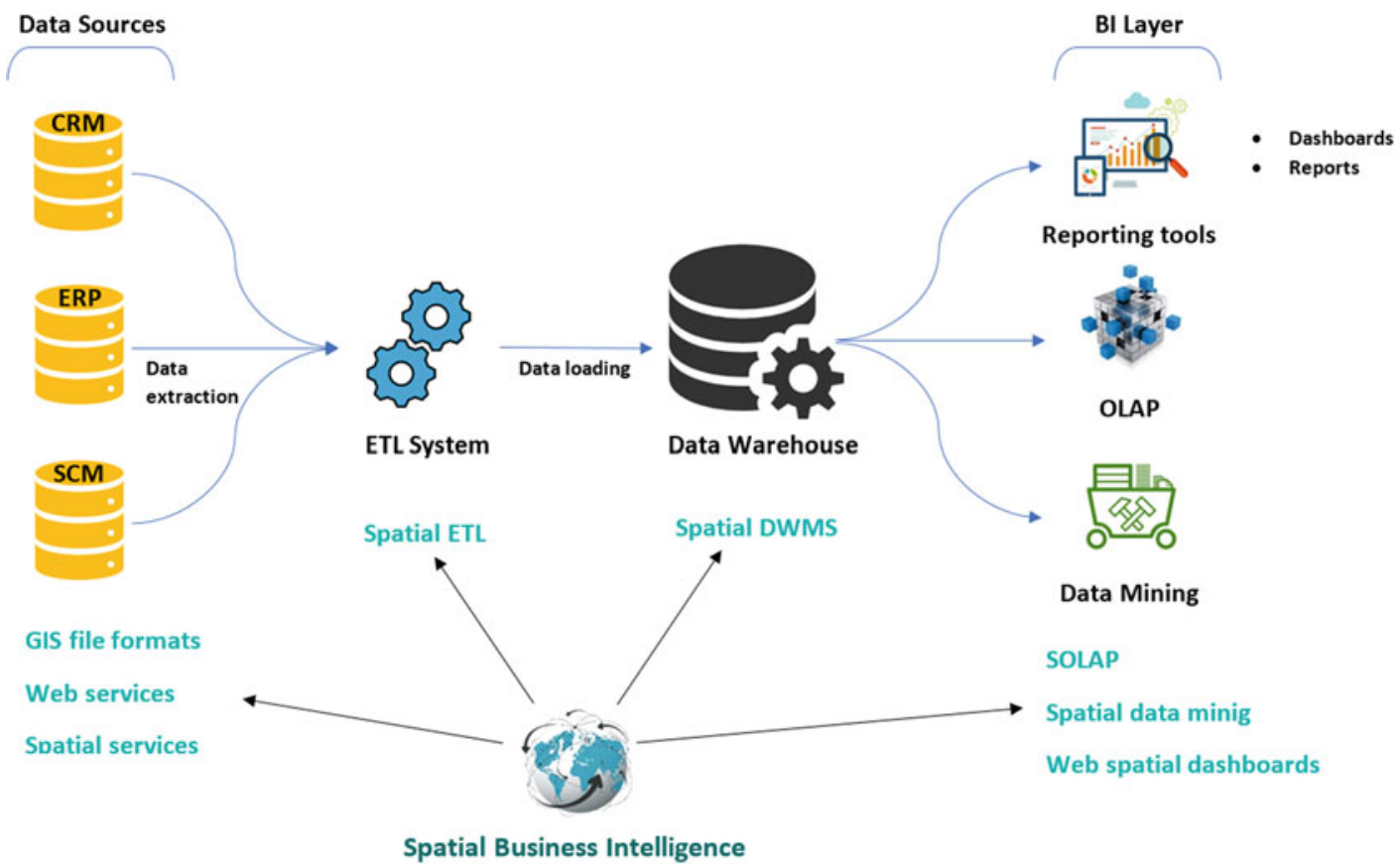

Fig. 4.9 From BI to spatial BI 
performing quick visual decoding and comparison of data. Data gains immediate visual impact with the help of maps, more emphatically true for data with a spatial dimension (Rivest et al. 2005). Maps best represent spatial phenomena or relationships such as the flow of proximity, while also facilitating visualisation of statistical measures for an area or region. In addition, maps allow multi-measure displays.

Today's GIS recognises the location component of data and associates data with geographic features maintained in a GIS. Features in a GIS are graphic representations of actual features, such as roads, rivers, and forests, and conceptual features such as political boundaries or service areas (Fig. 4.10). Associating data with features lets users organise data based on the geographic location of each record in the data. This geographic organisation, presented as a map, reveals spatial relationships and influences that cannot be identified in traditional tabular views of data.

Geographically organising data allows the utilisation of new data that may not have anything in common with existing data other than location. For instance, GIS analysts for insurance companies can map the addresses of insured structures and overlay floodplain boundaries to identify all structures within the floodplain. With this information, they can calculate the total financial impact on reserves from a potentially catastrophic flood. Other organisations, private and public, can perform this same analysis to determine the potential impact on facilities, supply chain, and employees. By carrying out spatial analysis using varied BI tools, decision-makers are able to better understand the historical, current and future aspects of business operations, derive useful insights and make the most effective decisions for their business.

GIS and BI were being implemented as the IT landscape was evolving to embrace common ways of compiling, storing, using, and distributing data. Knowing how BI and GIS were deployed in organisations presented opportunities for the proliferation of these technologies. If BI and GIS applications could work together, the benefits of these respective technologies could be realized by operational units not currently using both technologies. This would result in integrated applications expanding throughout the enterprise. Innovators in the public sector who wanted to extract more actionable information from existing data came to the same conclusion. Exposure to "new" technologies in the context of homeland security raised interesting possibilities for improving processes not

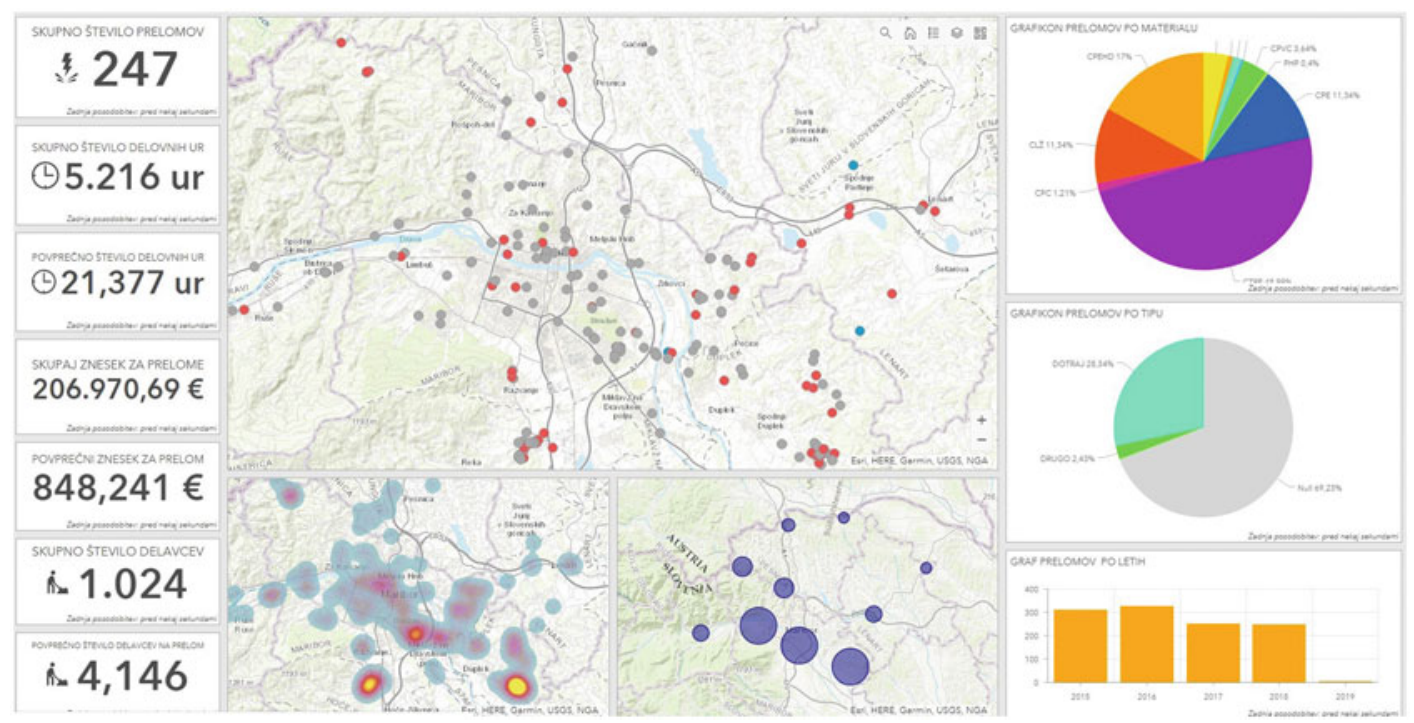

Fig. 4.10 GIS-based dashboard visualising information for managers 
directly related to homeland security. The fact that public agencies were looking at BI with the idea of integrating it with GIS was not lost on the BI providers whose success in the private sector had not been matched in the public sector. Business charting abilities of BI applications, conversely, GIS brings unique charting capabilities to BI in the form of spatial relationship and distribution charts. The portrayal of BI data as maps addresses a recognised shortcoming in BI graphics - the lack of context needed for informed decisions. For example, node-to-node supply chain performance data presented as bar charts or dashboards does not supply the location information needed for planning improvements. The same performance report presented as a map immediately shows spatial relationships between nodes that could explain variations in performance. Many organisations, both public and private, have come to understand the business cases for integrating BI and GIS and are actively exploring integration strategies (Wickramasuriya et al. 2013).

Most BI users are not accustomed to using maps as analytical tools. They typically analyse business data for patterns and trends using tables, charts, and graphs. They also benefit from OLAP data, which involves users analysing the major dimensions of business by drilling up and down through business data to uncover trends and anomalies. Although traditional BI tools are powerful and have delivered proven results, they do not incorporate a crucial component of most business information: location. Most business data contain some sort of location information: office locales, customer addresses, sales territories, marketing areas, facilities, and so on. When this data is viewed spatially on a map, patterns and trends that were once overlooked are clearly revealed.

When combining GIS with business intelligence data, organisations can answer questions like these (ESRI 2012):

- Who are my best customers and where are they located?

- Are there location-based patterns related to customers' purchase decisions?
- Where can I find potential customers like existing customers? Where have our marketing efforts been the most or least successful and why?

- Do we have customers at risk from physical phenomena, such as severe weather events, and what impact might that have on our business?

Answers to these and other critical questions are delivered through the successful integration of $\mathrm{BI}$ and GIS that provides the following (ESRI 2012):

- Powerful visual analysis capabilities for key BI data such as customers, retail outlets, assets and infrastructure, partner locations, supply chains, operational events, and utility grids

- Easy correlation of BI data with demographics, occupational classifications, lifestyle and socioeconomic factors, and consumer information to analyse and optimise product and service sales across multiple geographies

Immediate insight to enable rapid and informed decision making, including clear visualisation of what matters and where it matters, complemented with supporting business analytics, allowing knowledge workers to prioritise efforts and immediately become more productive.

Spatial analytics is increasingly becoming essential for obtaining accurate and actionable insight because there is a significant geographic dimension to every business transaction. There are two categories of industries. The first set is industries somehow naturally rooted in geographies like transport, telecommunication, or real estate, who depend on location-based information. The second set comprises of industries who not necessarily use geospatial data on an everyday basis, but they still depend on it for better performance. These would be retailers, insurance, banking (Devillers et al. 2007). Following industries are actively bringing spatial analytics to $\mathrm{BI}$ : 
- Retail industry: Along with physical store level detail, spatial analysis is helping the industry to gain invaluable insights in stock delivery, store management, inventory management, marketing and sales

- Healthcare: healthcare providers use spatial analytics to see issues from a location perspective, leading to more efficient practices and higher standards of patient care

- Banking: location data and analytics of customers help banks to carry out effective customer segmentation and profiling, develop more successful marketing and sales campaigns, tailor products and services according to the customer base within each region or division and identify and actively retain and pursue profitable customers,

- Insurance: Spatial analytics of location-based data, such as crime rates, weather patterns etc. is enabling insurance companies to identify high or low-risk cases and develop marketing strategies, policies and pricing models accordingly.

- Telecommunications: Spatial analytics enable the industry to assess strengths of the current infrastructure, analyse competitor network coverage etc. Understanding which locations will provide the best network coverage at the lowest costs possible helps the industry to function more effectively.

- Airports and airlines: Airlines use spatial analytics to track flight operations more closely and accurately. Airport, meteorological, and fleet data are monitored in real time, and operations crew reroute flight paths to optimise fuel and staff costs.

- Education: Adding a geographical component to students data enable higher education institutions to develop more effective marketing campaigns, understand better where to put facilities, and work on research grants.

- Energy: Spatial analytics is enabling the energy industry to discover patterns and uncover hidden insights in seconds rather than minutes and hours.
- Transport and logistics: Spatial analytics is helping to determine fastest transportation routes, enabling effective forecasting, optimising warehousing processes and stock flows based on consumption rates of particular products by locality.

More and more industries are integrating spatial analytics in BI as such a system provides more comprehensive information. Spatial analytics can be used to gain operational, transactional and competitive advantage (Devillers et al. 2007).

More and more vendors of BI platforms and tools like Tableau (2018) are embedding spatial analytics functionality in their solutions. Tableau is enabling instant geocoding and automatically turns the location data into interactive maps with 16 levels of zoom or alternatively enables the use of custom geocodes to map what matters for the business. Tableau supports Choropleth maps, Proportional symbol maps, Point distribution maps, Flow maps, origin-destination spider maps, Heath maps, etc.

Open Geospatial Consortium (OCG) develops standard protocol Web Map Service (WMS) which is a standard protocol for serving georeferenced map images over the internet that are generated by a map server using data that is typically sourced from GIS database. Recently it becomes well recognised and deployed standard. The Map intelligence WMS capability provides a standard generic method of exchanging data between Business Intelligence tools and map servers capable of handling WMS. These removes two major concerns for companies which want to utilise their organisation's BI data views. BI vendors' platforms for which there is a Map Intelligence (MI) Client, can use map servers that can provide WMS - these are: Esri ArcGIS Server, Spectrum spatial, GE Smallworld, GeoWebPublisher, GeognoSIS, GeoMedia, Oracle MapViewer, ObjectFX Web Mapping Tools, LizardTech Express Server and SuperMap and also open source GeoServer and MapServer. 


\subsection{Bibliometric Analysis of Research Publishing on Spatial Data Issues in Business Information Systems}

\subsubsection{Background, Aims and Scope of the Bibliometric Analysis}

In previous sections, we focused mainly on platform/solution/tools vendors viewpoints connected with functionality embedded in their software. In this section, we will discuss the research on spatial data issues in business information systems. Using the bibliometric study, we aim to identify the stage of integration of the two fields, namely:

- Enterprise Resource Planning (ERP) and Geographical Information Systems (GIS),

- Business Intelligence (BI) and Geographical Information Systems (GIS).

We analysed the development in the past period, and we want to identify the future development trends within these fields, as well. Therefore, the main objectives of the bibliometric study answered the questions, what are the dynamics of research literature production in the area of ERP and GIS integration on one side, and BI and GIS integration on the other side, and which are the most productive research topics in this field.

There are some the most widely known definitions of the bibliometric research: Hawkins (2001) defined bibliometrics as "the quantitative analysis of the bibliographic features of a body of literature", consist of bibliographic units - books, monographs, reports, theses, and papers in serials and periodicals are analysed. For analysing research literature production (to identify patterns in the literature), the bibliometric analysis uses quantitative methods (De Bellis 2009). Moreover, Garfield (2009) is convinced that with bibliometric analysis, we can also examine "the history and structure of a field, the flow of information into a field, the growth of the literature, the patterns of collaboration amongst scientists, the impact of journals, and the long-term citation impact of a work".

We performed the bibliometric analysis by using the Scopus database (on December 20, 2018). The Scopus database was selected, because it is easy to use, and it is also easy to transfer data into the program VOSviewer (Leiden University, the Netherlands) for further data analysis (van Eck and Waltman 2013). Namely, the VOSviewer was used in the second step of the bibliometric analysis, to obtain the bibliometric maps.

Bibliometric mapping is used with the purpose to represent scientific publications based on bibliographic data visually. With bibliometric mapping, we can produce different bibliometric maps which provide an overview of the structure of the scientific publications in a specific research field. One of the most popular ways to use bibliometric mapping is to identify specific research areas within a selected science field, with the purpose of getting a view of the size of the field and relevant subfields, and how they relate to each other (van Eck 2011). The VOS mapping technique has been implemented in a computer program, called VOSviewer (Leiden University, Netherlands) (van Eck and Waltman 2013), that is available at www.vosviewer.com. The VOSviewer software has visualisation capabilities. Therefore bibliometric maps can be displayed in various ways and consequently emphasise different aspects of a map. Additionally, VOSviewer allows for the use of different colours to indicate clusters of objects. Moreover, the VOSviewer software also merges terms that may be closely related to term clusters denoted by the same cluster colour (van Eck 2011). According to van Eck, the proximity of the terms can be interpreted as an indication of their relatedness. 


\subsubsection{Research Publishing on Enterprise Resource Planning (ERP) and Geographical Information Systems (GIS)}

In the first part of the bibliographic analysis, the search results from the Scopus database were obtained by using the "enterprise resource planning" key-phrase at the first level. A search revealed 12,906 bibliographic units that included this key-phrase in the title, keywords or in abstract. In the second step, the "GIS" keyword was used to identify the bibliographic units identified within the first step, that included both, "enterprise resource planning" and "GIS" key-phrases. The search revealed 40 units published between 1998 and 2018.

The search in Scopus database revealed, that the first two identified bibliographic units, that combines Enterprise Resource planning - ERP and Geographic(al) Information System - GIS, date to 1998 (although Scopus identifies three units, as presented by Fig. 4.1, two are identical). In his article, author Wilson (1998) discussed that Enterprise Resource Planning (ERP) and GIS are offering new opportunities for utility applications; article presented the IS/GIS integration, cost benefits, organisational re-engineering, as well as the geospatial implications. In the other article (Anon 1998) different software solutions that were used to predict the hydraulic behaviour of water distribution networks, to manage all data related to network assets, customer location and billing, and to demand profiles, pump curves and schedules, were discussed. On the other hand, a new software package was designed to help organisations to collate, evaluate and report corporate environmental information.

While no bibliographic units, covering the enterprise resource planning and GIS, were identified by Scopus in 1999, in 2000 and 2001 one per year were identified. A particularly interesting paper was published in 2000 (Zipf 2000), where the technology-enhanced project management in the Port Authority of New York and New Jersey was discussed. Author has stressed the importance of integrated project management systems, including GIS, electronic project management systems and enterprise-wide database systems; he argued that these technologies made it possible for timely information to be provided to project managers so that they could manage the project more effectively.

In 2004, a paper, covering the importance of integration of the Enterprise Resource Planning and GIS, in a field of tourism industry was presented to the professional public (Yan et al. 2002). Authors presented the advantages of an integrated information system of the tourism industry including its construction and functional realisation. The fusion of spatial information in the ERP system is discussed, and a spatially integrated information scheme is proposed.

After 2004 the number of publication was on average increasing - a positive trend is identified, with the peak in the volume of publications in 2006 in 2010, with 5 and 4 bibliographic units published.

That the 2004-2006 was the period when the "basic" research results on the integration of ERP and GIS were developed and publish, is also suggested by the analysis of the citations. The two most frequently cited bibliographic units, both with over 40 citations, are from 2005 (Li et al. 2005) with 61 citations, and from 2004, with 44 citations (Gayialis and Tatsiopoulos 2004). Li et al. (2005) presented a study on applying an integrated Global Position System (GPS) and Geographical Information System - GIS technology to the reduction of construction waste, where the integrated GPS and GIS technology is combined to the Enterprise Resource Planning system. Authors presented a case study with the purpose to demonstrate the deployment of the system that resulted in the minimisation of the amount of onsite material wastage.

The second highly cited publication (Gayialis and Tatsiopoulos 2004), presents the development of a decision support system used by an oil downstream company for routing and scheduling purposes. The delivery process of oil products from a number of distribution centres to all 
customers is very complex. The development of the operations research enabled the development of applications of the advanced planning and scheduling systems, that can be applied in practice if they are embodied in packaged information technology solutions. The second important condition is that the interface problems to mainstream ERP software applications are solved. In this study, the utilisation of advanced IT systems supports the planning and management of distribution operations effectively. This study shows that the combination of a supply chain management application with a geographical information system (GIS) integrated with an enterprise resource planning (ERP) software resulted in the innovative decision support tool; its' use may have many benefits: optimal use of the distribution network resources, transportation cost reduction and customer service improvement.

In the second step of the bibliometric analysis, the identified set of 40 bibliographic units were used in the mapping of clusters by using the VOSviewer.
In VOSviewer, based on the title and abstract the relevant terms were identified. The minimum number of occurrence of a term was set to 3 . Out of 1186 terms, identified by VOSviewer, 76 met the threshold. For each of the 76 terms, the relevance score was calculated, and the most relevant terms were selected $(60 \%$ the most relevant terms). This process resulted in the identification of 46 terms. After deleting terms that are general and not associated with the topic investigated (article, research, country etc.), the process of mapping of terms was performed. Three clusters were identified, that is presented in Fig. 4.11.

Results reveal that three clusters are observed. The common characteristics of bibliographic units in a green cluster are defined by terms of resource planning, organisation, management efficiency, implementation. Thus, the bibliographic units in this cluster relate with terms associated in particular to management. The bibliographic units in the red cluster contain terms like an information system, support, function and optimisation, while in the blue cluster, in particular terms GIS, GIS

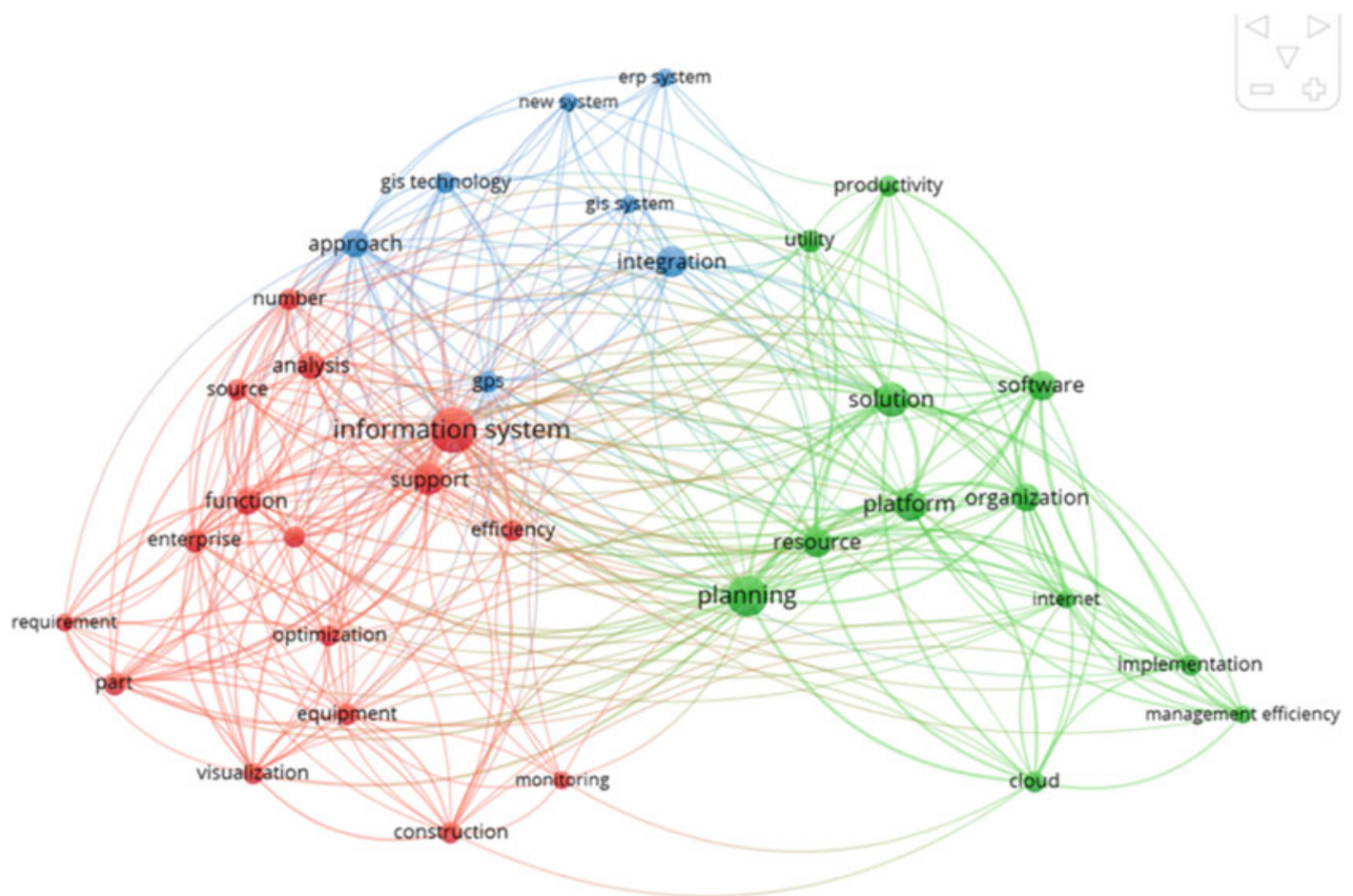

Fig. 4.11 Clusters - mapping of terms for "enterprise resource planning" and "GIS" key-phrases 
technology, GIS system, ERP and integration are the most emphasised.

The three clusters are interrelated, and the dense net of connections is visible among the terms within each cluster, and among terms between clusters, as well. If the term integration is put into the central place, the most emphasised connections are presented in Fig. 4.12.

Figure 4.12 shows that the integration of GIS, ERP, information system and software solution is very topical for research as well as for the implementation in organisations.

\subsubsection{Research Publishing on Business Intelligence (BI) and Geographical Information Systems (GIS) Integration}

The second part of the bibliometric analysis was also performed based on the Scopus database; we used the "business intelligence" key-phrase at the first level. A search revealed 6631 bibliographic units that included this key-phrase in the title, keywords or in abstract. In the second step, the "GIS" keyword was used to identify the bibliographic units identified within the first step, that included both, "business intelligence" and "GIS" key-phrases. The search revealed 112 units.

The first article that was identified in Scopus and is combining the Business Intelligence and the Geographical Information Systems was published in 2002. In their conference paper authors (Osianlis and Arnott 2002) presented the use of data warehousing and business intelligence technologies in an Australian water business for the management of water and waste-water services provision.

In 2004 two bibliographic units were identified; Weigang et al. (2004) presented a dynamic information system for urban bus passengers in Brasilia, using business intelligence, that was developed to optimise bus operations and increase the satisfaction of urban transportation users. To achieve these objectives,

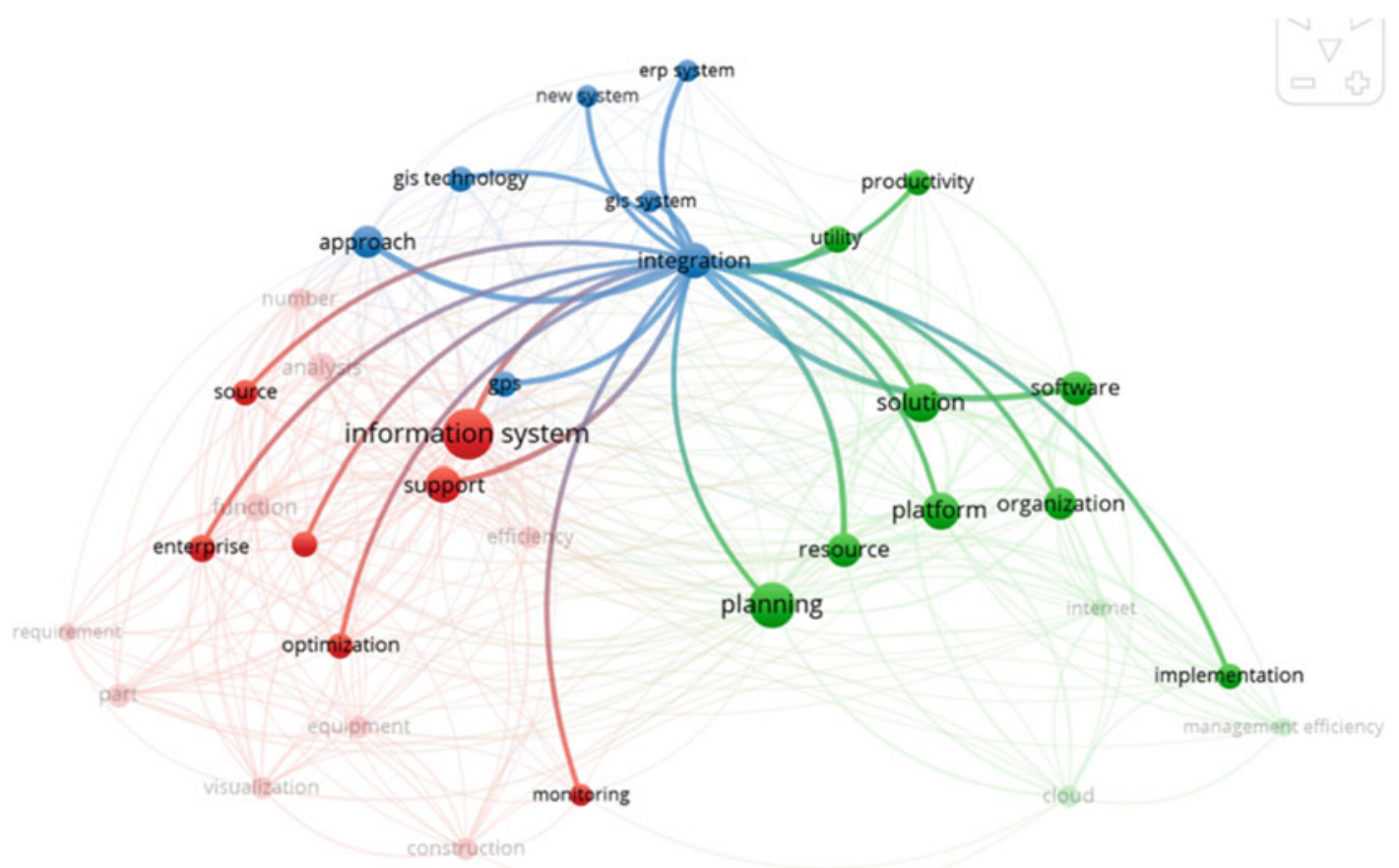

Fig. 4.12 The most emphasised connections with the term integration - "enterprise resource planning" and "GIS" key-phrases 
the system involves the convergence of a number of different technologies, including Global Positioning System (GPS), Geographic Information System, database, data mining, Internet and telecommunications. Thrall (2005) presented the software solution that provides the essential tools and functionality needed for deriving geospatial business intelligence, while Barnes (2005) emphasized many "layers" of GIS in today's business and everyday life: GIS plays a key role in natural resource extraction, infrastructure management, intelligence and military defence, homeland security, business intelligence, navigation, etc.

In 2005, a groundbreaking bibliographic unit was published that links BI and GIS, which to date is the most widely cited reference (108 citations) in the Scopus database in this integrated area. The authors (Rivest et al. 2005) emphasise the importance of on-line analytical processes in which companies combine data warehouses and analytical tools to access, visualise and analyse their integrated, aggregated and summarised data. The authors emphasise that a large part of this data has a spatial component, so they emphasise the importance of spatial online analytical processing, which allows interactive spatial-time data exploration. The purpose of their paper is to show how these concepts support spatial-temporal research of data with geo-visualisation, interactivity and animation options.

The number of published bibliographic units was constantly increasing, and in 2007 the bibliographic unit with the next highest number of citations was published. Authors (Devillers et al. 2007) emphasise that geospatial data users are often facing the need to assess and understanding the data quality, that is a complex task that may involve thousands of partially related metadata. The combining concepts of GIS and Business Intelligence represent such a complex case where heterogeneous datasets have to be integrated. Authors, therefore, describe and present the approach, that provides interactive, multigranularity and context-sensitive spatial data quality indicators that help experts to build and justify their opinions and business decisions.
The highest number of publications was in 2012 (14 bibliographic units); in the years to 2018, the number of published bibliographic units covered by Scopus ranges around 10 per year. The latest publications in 2018 show, how the integrated approach of GIS and BI may be beneficial for different aspects of quality of life of different social groups (Szewrański et al. 2018a), for detecting and predicting the flood risks for improving the water management infrastructure modelling (Szewrański et al. 2018b), for market segmentation and visualization, based on user behavior geographical distributions (Kamthania et al. 2018) etc.

In the second step of the bibliometric analysis, the identified set of 112 bibliographic units was used in the mapping of clusters by using the VOSviewer.

In VOSviewer, based on the title and abstract the relevant terms were identified. The relevance score was calculated, and the most relevant terms were selected; the process resulted in the identification of 51 terms. After deleting terms that are general and not associated with the topic investigated (article, research, country etc.), the process of mapping of terms was performed. Two clusters were identified, that is presented in Fig. 4.13.

Results reveal that two clusters are observed. The common characteristics of bibliographic units in a red cluster are defined by terms of business intelligence, decision making, decision support systems, data, analysis. Thus, the bibliographic units in this cluster relate with terms associated in particular to business intelligence and business decision-making process. The bibliographic units in the green cluster contain terms associated with the information systems and the geographic information systems, performance, knowledge and effectiveness. The two clusters are interrelated, and the dense net of connections is visible among the terms within each cluster, and among terms between clusters, as well.

The results of both bibliometric analyses therefore confirm, that integration of both fields, namely, the Enterprise Resource Planning and the Business Intelligence, with Geographic Information Systems, is very topical and important 


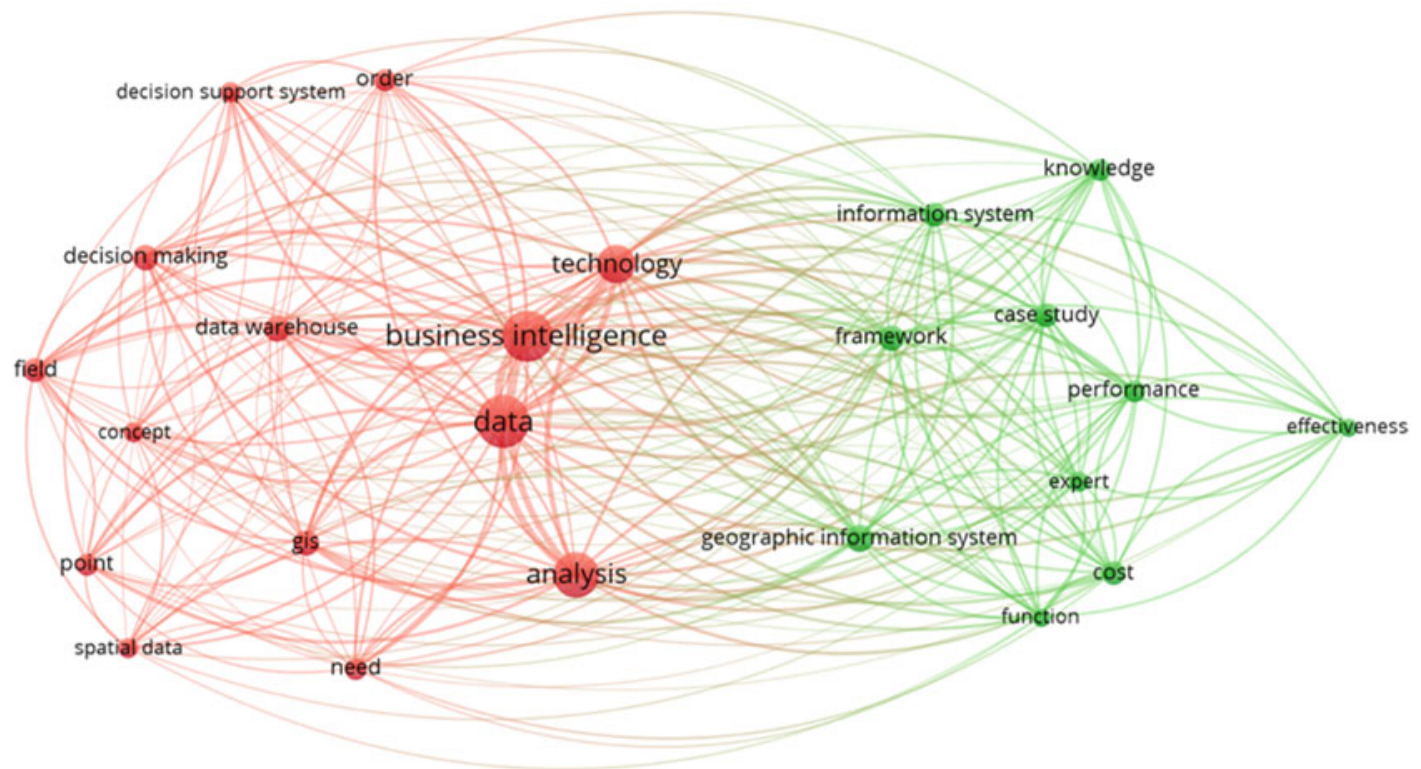

Fig. 4.13 Clusters - mapping of terms - "business intelligence" and "GIS" key-phrases

field in academic research as well as in the applied field, especially in the field of business decision making, by providing information, that could not be gathered without such an integration (or, at least, could not be captured on such a quality level). Linking ERP and BI with GIS thus represents an important quality information basis for business decision making.

\subsection{Conclusion}

Organisation-wide information systems like ERP, $\mathrm{CRM}$ and $\mathrm{BI}$, are core information systems of organisations because they provide core and crucial support for daily operations/business activities. They are used in nearly every company/organisation. They are also already mature technologies - solutions available on the market offered by providers belong to third wave/generation. They are not only technological sophisticated, but they are also following the demands and expectations of organisations. Solutions providers are expanding their functionality all the time by adding new modules and features. A new generation of solutions can be easily integrated with other information systems which are more specialised in a certain area. One such category of information systems is GIS. Their use is expanding more and more to business processes, and therefore more and more organisations are starting to use GIS. Years ago they were used as stand-alone systems, but recently they are in many companies integrated with other information systems. In such a way they become an important part of information support to the operational level and also to management level. At the operational level, they are primarily used in companies with location-based business events, with location-based resources and with location-based workflows (i.e. route planning). At management level companies are using GIS-enabled reporting with GIS-based dashboards.

\section{References}

Abou-Ghanem, M. \& Arfaj, K. A. (2008). SAP/GIS integration case studies \& techniques. Retrieved from https://pdfs.semanticscholar.org/6a84/

21e2698462aa8e47a8cfc537639a8825788b.pdf (20.12.2018).

ACC Software Solutions. (2018). Future-proof your business with postmodern ERP (e-book). NJ: ACC 
Software Solutions. Retrieved from https://4acc.com/ future-proof-with-postmodern-erp-ebook/ (18.10.2018).

Almajali, D. A., Masa'deh, R., \& Tarhini, A. (2016). Antecedents of ERP systems implementation success: A study on Jordanian healthcare sector. Journal of Enterprise Information Management, 29(4), 549-565.

Anderegg, T. (2000). ERP: A-Z Implementer's guide for success. Resource Pub.

Anon, J. (1998). Information technology and GIS. Water Services, 102(1225), 20-22.

Aydin, A. O. \& Sarman, S. (2006). A management information system: Integrating GIS, GPS and ERP. In The Proceedings of the 4th International Logistics and Supply Chain Management Congress, Turkey.

Barnes, S. (2005). The many layers of GIS. GeoSpatial Solutions, 15(7), 26-29.

Bidgoli, H. (2004). The internet encyclopaedia (Vol. 1). Hoboken: Wiley.

Bimonte, S., Tchounikine, A., Miquel, M., \& Pinet, F. (2010). When spatial analysis meets OLAP: Multidimensional model and operators. International Journal of Data Warehousing and Mining, 6(4), 33-60.

Bradford, M. (2016). Modern ERP: Select, implement and use Today's advanced business systems. Raleigh, NC: North Carolina State University (lulu.com.

Buttle, F., \& Maklan, S. (2015). In London/New York: Routledge/Taylor \& Francis Group (Ed.), Customer relationship management: Concepts and technologies (3rd ed.).

Chen, H., Chiang, R. H. L., \& Storey, V. C. (2012). Business intelligence and analytics: From big data to big impact. MIS Quarterly, 36(4), 1165-1188.

Chorianopoulus, A. (2016). Effective CRM using predictive analytics. West Sussex: Wiley.

Chung, W., Chen, H. \& Nunamaker Jr, J. F. (2002). Business intelligence explorer: A knowledge map framework for discovering business intelligence on the web. HICSS'03.

De Bellis, N. (2009). Bibliometrics and citation analysis. Lanham, MD/Toronto/Plymouth, UK: The Scarecrow Press, Inc.

Devillers, R., Bédard, Y., Jeansoulin, R., \& Moulin, B. (2007). Towards spatial data quality information analysis tools for experts assessing the fitness for the use of spatial data. International Journal of Geographical Information Science, 21(3), 261-282.

ESRI (2007). GIS best practices - Using GIS and SAP. Retrieved from https://www.aeroterra.com/PDF/usinggis-and-sap.pdf (15.10.2018).

ESRI (2012). ESRI location analytics for business intelligence. Retrieved from https://www.esri.com/library/ whitepapers/pdfs/esri-location-analytics-for-bi.pdf (15.10.2018).

ESRI (2018). Esri maps for dynamics CRM. Retrieved from http://doc.arcgis.com/en/maps-for-dynamics$\mathrm{crm} /(20.11 .2018)$.

Ganly D., Kyte A., Rayner N., \& Hardcastle C. (2013). Predicts 2014: The Rise of the Postmodern ERP and Enterprise Applications World. Retrieved from https://
www.gartner.com/doc/2633315/predicts\%2D \% 2Drise-postmodern-erp (10. 3. 2017).

Garfield, E. (2009). From the science of science to Scientometrics visualizing the history of science with HistCite software. Journal of Informetrics, 3, 173-179.

Gayialis, S. P., \& Tatsiopoulos, I. P. (2004). Design of an IT-driven decision support system for vehicle routing and scheduling. European Journal of Operational Research, 152(2), 382-298.

Gideon Adewale, A., Gideon Olukunle, B. \& Ede, A. (2016). Geographic information systems application in sustainable business intelligence analysis. 3rd International Conference on African Development Issues. Covenant University Press.

Hawkins, D. T. (2001). Bibliometrics of electronic journals in information science. Information Research, 7, 1. Retrieved from http://InformationR.net/ir/7-1/ paper120.html (20.12.2018).

Hessa, R. L., Rubin, R. S., \& West, L. A. (2004). Geographic information systems as a marketing information system technology. Decision Support Systems, 38 (2), 197-212.

Horwitt, E. (2009). ERP and GIS integration brings spatial dimension to key business apps. Search Manufacturing ERP. Retrieved from https://searcherp. techtarget.com/news/1373664/ERP-and-GIS-integra tion-brings-spatial-dimension-to-key-business-apps (20.12.2018).

Howson, C. (2014). Successful business intelligence Unlock the value of BI \& Big Data (2nd ed.). New York: Mc Graw Hill Education.

HubPages. (2018). Enterprise Resource Planning (ERP) and Fortune 500 Companies (2017).Retrieved from https://hubpages.com/business/Enterprise-ResourcePlanning-ERP-and-Fortune-500-Companies (18.7.2018).

Kamthania, D., Pahwa, A., \& Madhavan, S. S. (2018). Market segmentation analysis and visualisation using $\mathrm{K}$-mode clustering algorithm for E-commerce business. Journal of Computing and Information Technology, 26(1), 57-68.

Li, H., Chen, Z., Yong, L., \& Kong, S. C. W. (2005). Application of integrated GPS and GIS technology for reducing construction waste and improving construction efficiency. Automation in Construction, 14(39), 323-331.

Litan, D., Mocanu, A.-M., Copcela, L., Surugiu, I., Teohari, M., \& Raduta, O. (2011). Business' new requirement: Information systems integration Methods and technologies. International Journal of Computers and Communications, 3(5), 133-145.

Lizzote, O. (2017). Do you CRM me?: An analytical guide to customer relationship management. North Charleston: CreateSpace Independent Publishing Platform.

Magal, S. R., \& Word, J. (2011). Integrated business processes with ERP systems. Hoboken: Wiley.

Monk, E., \& Wagner, B. (2009). In Course Technology Cengage Learning Boston (Ed.), Concepts in Enterprise Resource Planning (3rd ed.). Boston.

Montgomery N., Anderson, R. P., Kostoulas J., and Woodyer A. (2018). High-tech Tuesday webinar: 
Best opportunities and bets for growth in Enterprise Resource Planning. Retrieved from https://www. gartner.com/doc/3640429?ref=SiteSearch\& sthkw $=$ postmodern $\% 20$ erp $\& \mathrm{fnl}=$ search $\& \operatorname{srcId}=1$ 3478922254 (20.5.2018).

Nussbauman, K. C. (2015). Storytelling with data: A data visualization guide for business professionals. New Jersey: Wiley.

Osianlis, A., \& Arnott, D. R. (2002). The application of business intelligence and data warehousing in an Australian water business. Management Information Systems, 369-378.

Patel, J. \& Doctor, G. (2013). Exploring Enterprise Resource Planning (ERP) and Geographic Information System (GIS) integration. Retrieved from https:// www.researchgate.net/publication/259462868_

EXPLORING_ENTERPRISE_RESOURCE_ PLANNING_ERP_AND_GEOGRAPHIC_INFOR MATION_SYSTEM_GIS_INTEGRATION (13.8.2018).

Pelphrey, M. W. (2015). Directing the ERP implementation: A best practice guide to avoiding program failure traps while tuning system performance. London: CRC Press.

Phillips, S. S. \& Ryan, E. (2013). Control your ERP Destiny: Reduce project costs, mitigate risks, and design better business solutions. US: Street Smart ERP Publications.

Posthumus, R. (2008). GIS as a tool in business intelligence. PositionIT. Retrieved from http://www.ee.co. za/wp-content/uploads/legacy/AppT-GIS\%20as\%20a $\% 20$ tool.pdf

Rivest, S., Bedard, Y., Proulx, M.-J., Nadeau, M., Hubert, F., \& Pastor, J. (2005). SOLAP technology: Merging business intelligence with geospatial technology for interactive spatio-temporal exploration and analysis of data. ISPRS Journal of Photogrammetry \& Remote Sensing, 60, 17-33.

Sherman, R. (2015). Business intelligence guidebook From data integration to analytics. Waltham: Elsevier.

SMRC (2017). ERP software market report 2017, trends, analysis, share, estimates and forecasts to 2022. Retrieved from http://www.mynewsdesk.com/us/ pressreleases/erp-software-market-report-2017-trendsanalysis-share-estimates-and-forecasts-to-20222287038. (5.6.2018).

Sneller, L. (2014). A guide to ERP - Benefits, implementation and trends. Bookboon.com.

Starzyczna, H., Pellešova, P., \& Stoklasa, M. (2017). The comparison of customer relationship management (CRM) in Czech small and medium enterprises according to selected characteristics in the years 2015, 2010 and 2005. Acta Universitatis Agriculturae et Silviculturae Mendelianae Brunensis, 65, 1767-1777.

Few, S. (2006). Information dashboard design: The effective visual communication of data. Cambridge, MA: O'Reilly.
Stepniak, C., \& Turek, T. (2014). Integration of spatial information resources on the example of utility companies in Czestochowa region. Online Journal of Applied Knowledge Management, 2(2), 97-108.

Szewrański, S., Chruściński, J., van Hoof, J., Kazak, J.K., Świader, M., Tokarczyk-Dorociak, K., Zmuda, R. (2018b). A location intelligence system for the assessment of pluvial flooding risk and the identification of stormwater pollutant sources from roads in suburbanised areas. Water (Switzerland) 10 (6), art. no. 746.

Szewrański, S., Świąder, M., Kazak, J. K., TokarczykDorociak, K., \& van Hoof, J. (2018a). Socioenvironmental vulnerability mapping for environmental and flood resilience assessment: The case of ageing and poverty in the City of Wrocław, Poland. Integrated Environmental Assessment and Management, 14(5), 592-597.

Tableau. (2018). Solutions maps. Retrieved from www. tableau.com/solutions/maps (8.10.2018).

Thrall, G. I. (2005). ESRI enables ArcGIS for business analyst. GeoSpatial Solutions, 14(6), 45-48.

Treiblmayer, M, Tso-Sutter, K. H. L., \& Krüger, A. (2011). Interfacing business processes and spatial processes. In Proceedings 2011 IEEE international conference on spatial data mining and geographical knowledge services, Fuzhou, 174-180.

Trieu, V.-H. (2017). Getting value from business intelligence systems: A review and research agenda. Decision Support Systems, 93, 111-124.

van Eck, N. J., \& Waltman, L. (2013). VOSviewer Manual. Leiden: Universiteit Leiden.

van Eck, N.J. (2011). Methodological advances in bibliometric mapping of science. PhD Series Research in Management, 247. Rotterdam: Erasmus Research Institute of Management.

Wan, J. \& Xie, L. A. (2018). Bibliometric review of research trends in Social CRM. Association for Information Systems, 2018. WHICEB 2018, 63. Retrieved from http://aisel.aisnet.org (19.8.2018).

Weigang, L., Yamashita, Y., Koendjbiharie, M. W., De Moura Juca, R. C., \& Maclver, A. (2004). The development and implementation of the operation system and data bank for the intelligent transportation system - Sitcuo. Journal of Advanced Transportation, 38(2), 163-186.

Wickramasuriya, R., Ma, J., Berryman, M., \& Perez, P. (2013). Using geospatial business intelligence to support regional infrastructure governance. Knowledge-Based Systems, 53, 80-89.

Wilson, J. D. (1998). Enterprise resource planning creates new opportunities for GIS in utilities. GIS World, 11 (5), 51-53.

Yan, L., Wang, J.-B., Ma, Y.-A., \& Dou, J. (2002). The Enterprise Resource Planning (ERP) system and spatial information integration in tourism industry Mount Emei for example. Lecture Notes in Computer Science, 2331(Part 3), 966-974. 
Yaptenco, E., Piepel, C., Rowland, B. \& Causley, M. (2005). Integrating GIS within the enterpriseoptions, considerations and experiences. ESRI International User Conference 2005. Retrieved from http:// downloads.esri.com/support/ProjectCenter/tw_1111_ Mark_Causley_PRES_1.pdf (20.10.2018).
Yerpude, S., \& Kumar Singhal, T. (2018). Internet of Things based Customer Relationship Management A Research Perspective. International Journal of Engineering \& Technology, 7(2.7), 444-450.

Zipf, P. J. (2000). Technology-enhanced project management. Journal of Management in Engineering, 16(1), 34-39.

Open Access This chapter is licensed under the terms of the Creative Commons Attribution 4.0 International License (http://creativecommons.org/licenses/by/4.0/), which permits use, sharing, adaptation, distribution and reproduction in any medium or format, as long as you give appropriate credit to the original author(s) and the source, provide a link to the Creative Commons licence and indicate if changes were made.

The images or other third party material in this chapter are included in the chapter's Creative Commons licence, unless indicated otherwise in a credit line to the material. If material is not included in the chapter's Creative Commons licence and your intended use is not permitted by statutory regulation or exceeds the permitted use, you will need to obtain permission directly from the copyright holder. 